\title{
Epidermal Enzymatic Biosensors for Sweat Vitamin C: Toward Personalized Nutrition
}

Juliane R. Sempionatto ${ }^{\S, 1}$, Ahmed A. Khorshed ${ }^{\S, 1}$, Aftab Ahmed ${ }^{1}$, Andre N. De Loyola e Silva ${ }^{1}$, Abbas Barfidokht ${ }^{1}$, Lu Yin ${ }^{1}$, K. Yugender Goud ${ }^{1}$, Mona A. Mohamed ${ }^{1}$, Eileen Bailey $^{2}$, Jennifer $\mathrm{May}^{2}$, Claude Aebischer ${ }^{2}$, Claire Chatelle², and Joseph Wang ${ }^{*}$

1. Department of Nanoengineering, University of California, 92093 San Diego, California, United States

2. DSM Nutritional Products, Analytical Sciences, 4303 Kaiseraugst, Switzerland

$\S$ Authors with equal contribution

*Corresponding author: josephwang@eng.ucsd.edu

Supporting Information

Video S1: Wearable nutrition tattoo transfer process.

Video S2: Integration of the conformal wearable nutrition platform with miniaturized wireless electronics for continuous data acquisition of the individual dietary profile. 


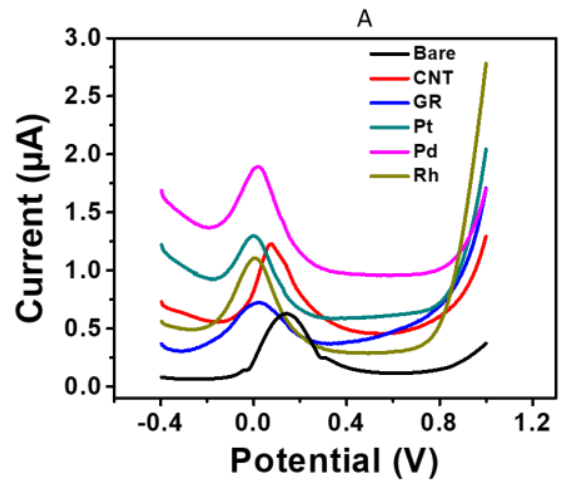

\begin{tabular}{|c|c|c|c|c|}
\hline \multicolumn{5}{|c|}{ B } \\
\hline $\begin{array}{l}\mathrm{S} \\
\text { No }\end{array}$ & $\begin{array}{l}\text { Gwent } C \text { ink } \\
+1 \% \text { catalyst }\end{array}$ & & Current $(\mu \mathrm{A})$ & Potential (V) \\
\hline 1 & Bare SPCE & \multirow{6}{*}{$\begin{array}{c}200 \mu \mathrm{M} \\
\text { Ascorbic } \\
\text { acid }\end{array}$} & 0.464 & 0.136 \\
\hline 2 & CNT & & 0.941 & 0.112 \\
\hline 3 & $\begin{array}{l}\mathrm{Pt} \\
1 \% \text { of the commercial } 3 \mathrm{wt} \% \text { Pt on } \\
\text { activated C }\end{array}$ & & 0.505 & 0.008 \\
\hline 4 & $\begin{array}{l}\text { Pd } \\
1 \% \text { of the commercial } 5 \text { wt\% Pd on } \\
\text { activated C }\end{array}$ & & 0.682 & 0.024 \\
\hline 5 & $\begin{array}{l}\mathrm{Rh} \\
1 \% \text { of the commercial } 5 \text { wt\% Rh on } \\
\text { activated C }\end{array}$ & & 0.701 & 0.008 \\
\hline 6 & Graphene & & 0.601 & 0.112 \\
\hline
\end{tabular}

Figure S1. (A) Square wave voltammograms (SWV) for ascorbic acid using bare screen-printed electrode, and with $1 \%$ CNT, $1 \%$ GR, 1\% Pt, 1\% Pd, 1\% Rh in PBS with $200 \mu$ M ascorbic acid concentration. SWV potential range, - 0.4 to $+1.0 \mathrm{Vvs}$. $\mathrm{Ag} / \mathrm{AgCl}$, using a frequency of $20 \mathrm{~Hz}$, and amplitude of $50 \mathrm{mV}$; (B) Summary table for material optimization.
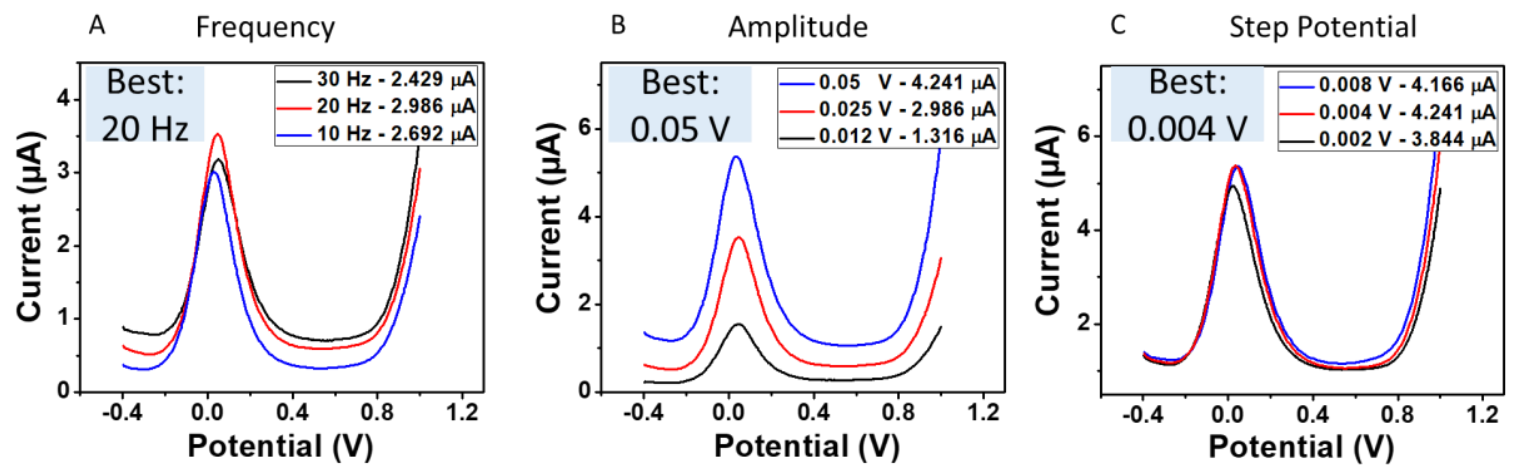

Figure S2. Effect of the square wave parameters. Square wave voltammogram for $500 \mu M$ vitamin $C$ in PBS concentration using screen printed electrode with $1 \%$ Rh at $(\boldsymbol{A})$ different applied frequencies $(10-30 \mathrm{~Hz}),(\boldsymbol{B})$ different applied amplitudes $(0.012-0.05 \mathrm{~V})$ and $(\boldsymbol{C})$ different applied step potentials $(0.002-0.008 \mathrm{~V})$. 

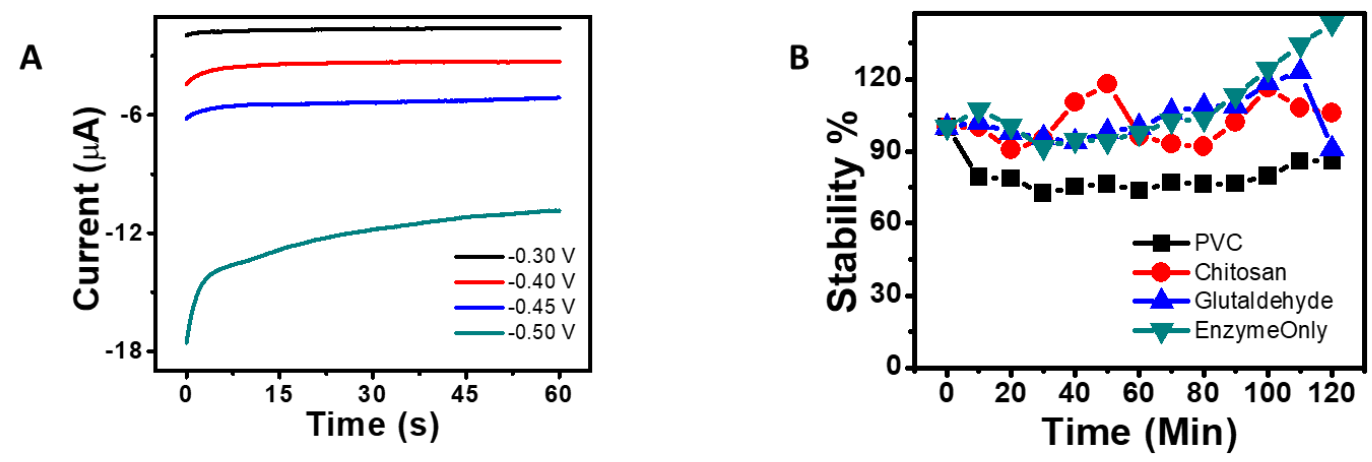

Figure S3. (A) Different detection potentials. Amperometric responses of $500 \mathrm{mM}$ of vitamin $C$ at detection potentials of $-0.30,-0.40,-0.45$, and $-0.50 \mathrm{~V}$. (B) Stability of vitamin $C$ responses using different polymers. Stability of the response of uncoated AAOx-modified screen-printed electrode and coated with $0.5 \mu \mathrm{L}$ of each of the following: chitosan $2 \%, P V C$ and glutaraldehyde at $0.5 \%$.
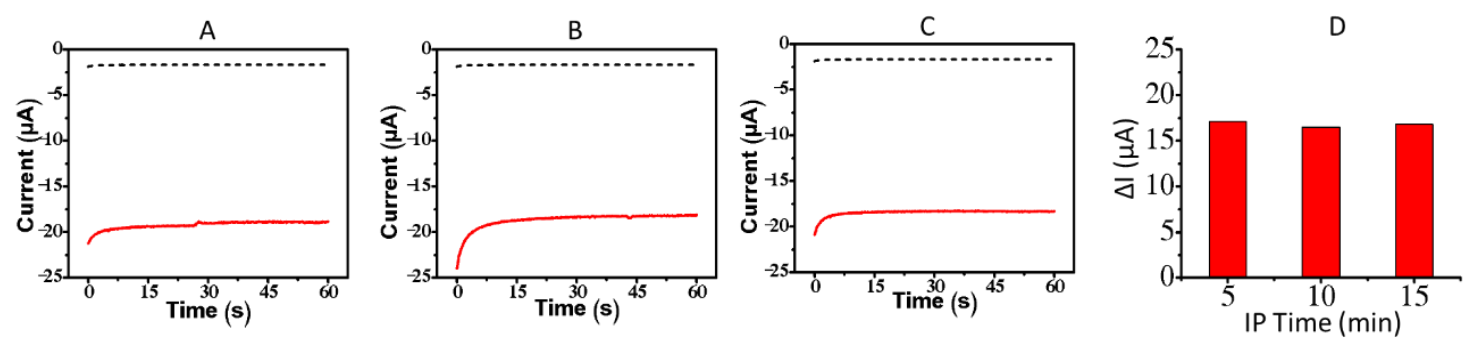

Figure S4. Amperometric responses of vitamin $C$ in simulated sweat before (dark dotted line) and after 90 minutes (solid red line) of taking $1000 \mathrm{mg}$ pill using (A) 5 (B) 10 and (C) 15 minutes IP. (D) Corresponding bar plot showing vitamin $C$ response after each stimulation. 

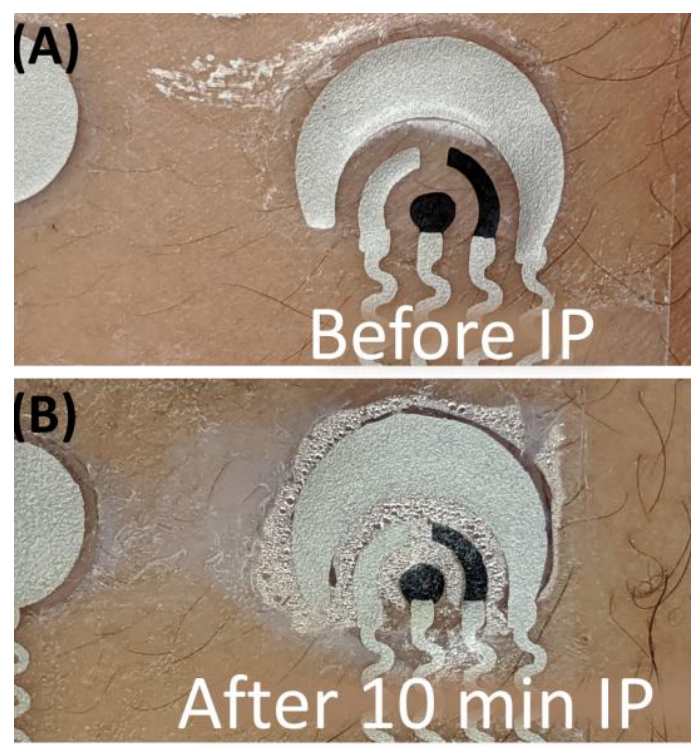

Figure S5. Photography showing the anode before $(\boldsymbol{A})$ and after $(\boldsymbol{B})$ the sweat stimulation. The stimulated sweat should be enough to cover all three electrochemical sensors for the vitamin C determination at $-0.5 \mathrm{~V}$.
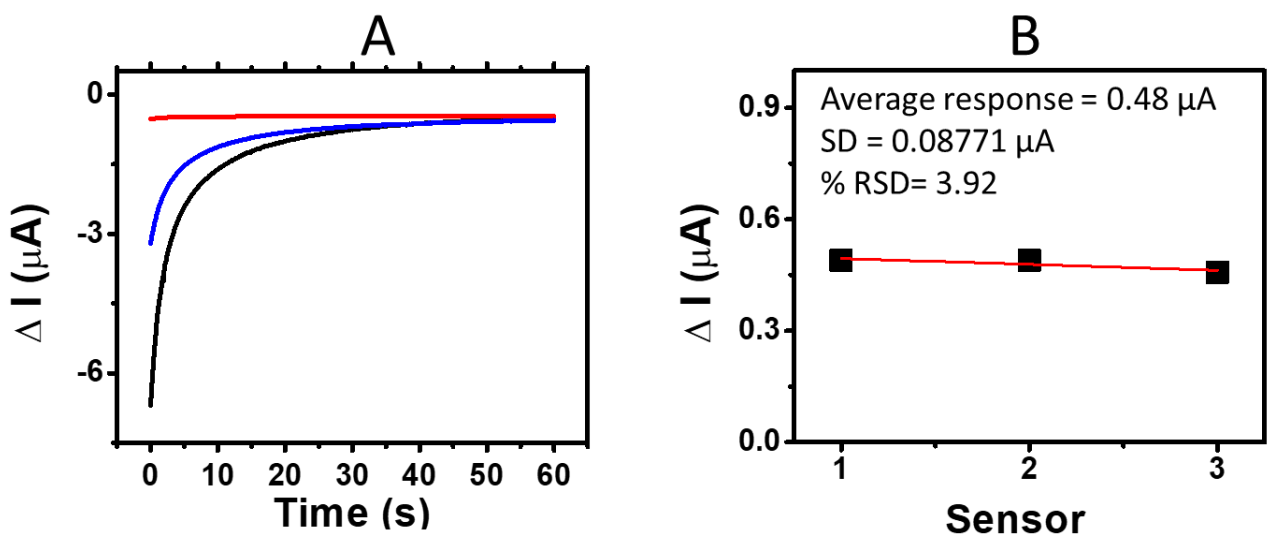

Figure S6. (A) Amperometric responses of $100 \mu \mathrm{m}$ ascorbic acid subtracted from PBS baseline from three different sensors at applied potential - $0.5 \mathrm{~V}(B)$ Respective plot (delta current values vs sensor number). 

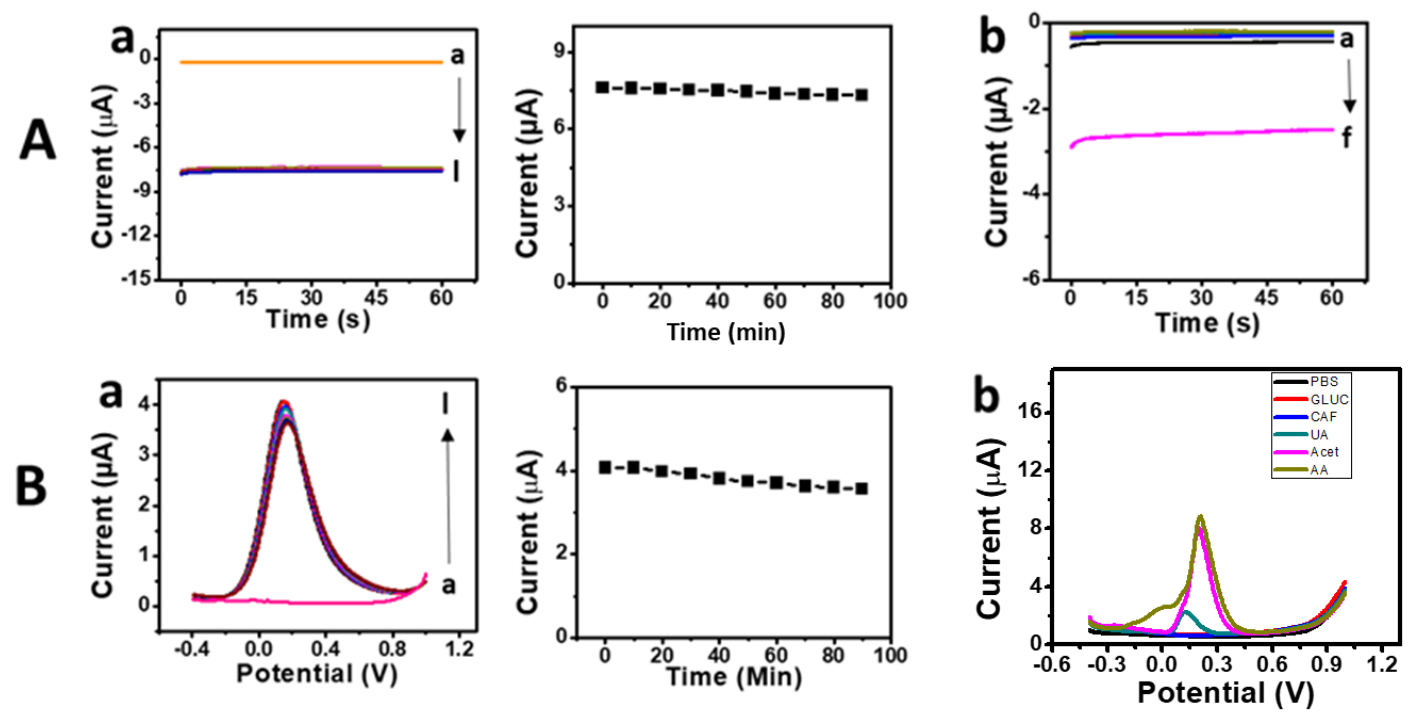

Figure S7. (A) (a) Chronoamperograms and respective plot for the stability of the $1 \mathrm{mM}$ vitamin $C$ response recorded at 10 min intervals (left) and final response at $60 \mathrm{sec}$ (right). (b) Selectivity test response in buffer solution: a-PBS baseline, b-caffeine, c-glucose, $d$-uric acid e-acetaminophen, $f$-vitamin $C$. (B) (a) $S W V$ (left) and respective plot (right) of final response at $60 \mathrm{sec}$ of vitamin $C$ in PBS from (a-l) for the stability study for ImM vitamin C signal measured every 10 minutes. (b) Selectivity test response in buffer solution: $a$-PBS baseline, $b$-caffeine, $c$-glucose, $d$-uric acid e-acetaminophen, $f$-vitamin $C$.

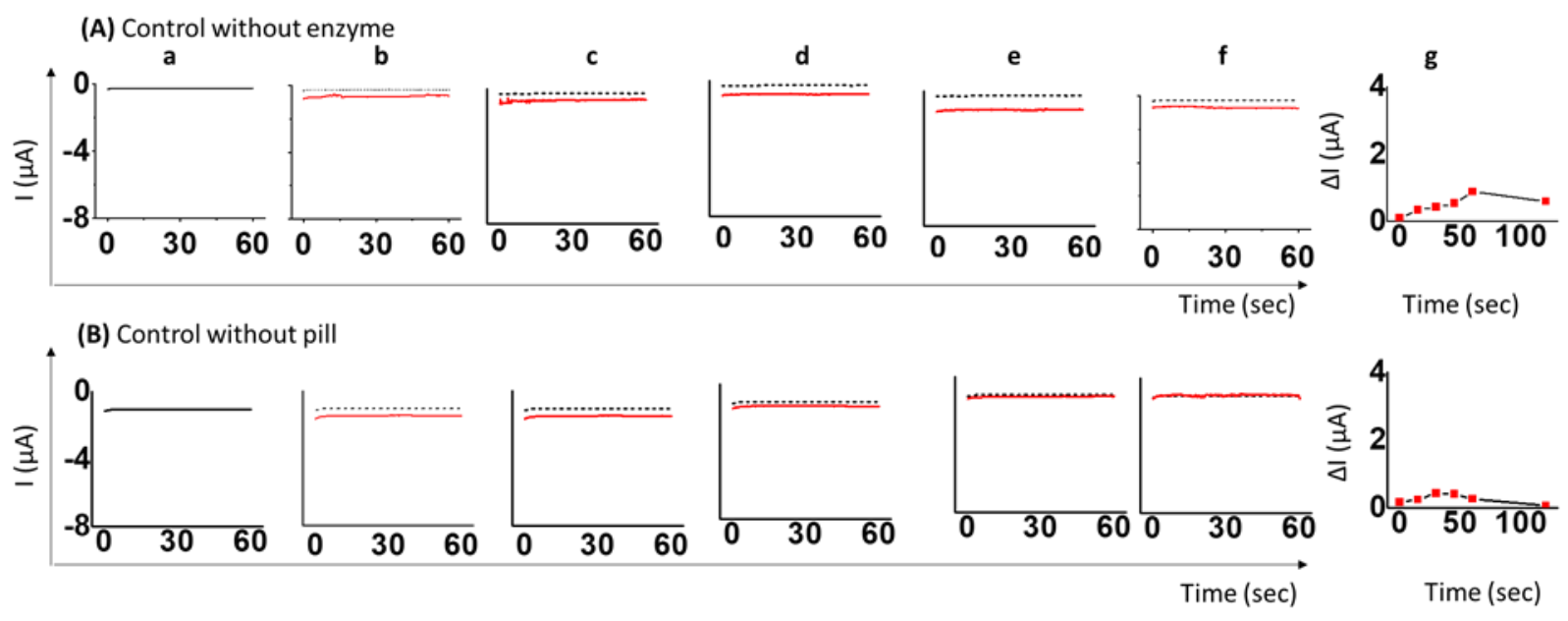

Figure S8. Control experiments for disposable strips in saliva samples. (A) Saliva signal before taking vitamin (dotted black line) and every 15 minutes after taking $1000 \mathrm{mg}$ vitamin C tablet (red solid line) ( $\mathrm{a}$ e) and after 2 hours of taking the vitamin pill (f). (B) Saliva signal before taking vitamin (dotted black line) and every 15 minutes until 1 h (a-e) and after 2 hours $(f)$ without taking any vitamin $C$ pill. The response for both analysis using the respective baselines are shown in figures $A(g)$ and $B(g)$. 